\title{
Feasibility Study Of Xiv Hiu Putih Housing, Palangka Raya City Based On Permenpera No 22/Permen/M/2008
}

\author{
Kelayakan Perumahan Hiu Putih Xiv Kota Palangka Raya \\ Berdasarkan Permenpera Nomor 22/Permen/m/2008 \\ Ardiansyah $^{1}$, Samuel layang ${ }^{2}$ \\ ${ }^{1}$ Mahasiswa Program Studi Pendidikan Teknik Bangunan \\ ${ }^{2}$ Dosen Program Studi Pendidikan Teknik Bangunan Universitas Palangka Raya \\ e-mail: ardiansyah.liber@gmail.com
}

\begin{abstract}
This study aims to assess the feasibility of housing type 36 which was built by PT. Toraa Graha Utama at the Perumahan Hiu Putih XIV Palangka Raya City, Central Kalimantan based on Permenpera Nomor 22/Permen/M/2008. The study refers to livable houses that apply a healthy and safe environment supported by public infrastructure, facilities and utilities regulated by technical guidelines for minimum service standards in the district/city housing sector. This study uses a descriptive qualitative method and uses analysis. The research instruments were in the form of questionnaires and interviews with informants. There are 30 house samples. Based on the results of the study, it is known that the Perumahan Hiu Putih XIV has implemented the provisions for livable houses, and meets the building safety requirements, minimum adequacy of building area and the health of its occupants, and has also implemented environmental criteria equipped with environmental infrastructure, and public facilities. The results of calculations from respondents' answers conducted at the time of the interview obtained $88 \%$ of the total achievement of livable houses and a healthy and safe environment supported by infrastructure, facilities and public utilities.
\end{abstract}

Keywords: Feasibility, housing, Permenpera Nomor 22/Permen/M/2008

\section{PENDAHULUAN}

Palangka Raya merupakan Ibu Kota Provinsi Kalimantan Tengah yang mengalami perkembangan cukup pesat. Hal ini membawa pengaruh pada berbagai bidang seperti meningkatnya kebutuhan akan rumah tinggal. Rumah tinggal dapat dibangun secara individu atau oleh pengembang (developer). Pembangunan perumahan di Kota Palangka Raya banyak dilakukan oleh developer swasta. Hal ini terlihat dari banyaknya berbagai tipe perumahan-perumahan sederhana di Kota Palangka Raya. Pembangunan perumahan, sarana dan prasarana harus mendapatkan perhatian yang serius karena rumah merupakan salah satu kebutuhan dasar (basic need) manusia. Oleh karena itu sudah selayaknya apabila pemerintah mengeluarkan peraturan perundang-undangan yang mengatur tentang perumahan dan pemukiman, yang dimaksudkan untuk memberikan arahan (guide line) bagi pembangunan sektor perumahan dan pemukiman.

Untuk menjamin agar pembangunan perumahan sesuai dengan standar dan spesikasi teknis, Menteri Perumahan Rakyat telah mengeluarkan Peraturan Menteri Negara Perumahan Rakyat Nomor 22/PERMEN/M/2008 tentang Standar Pelayanan Minimal Bidang Perumahan Rakyat Daerah Provinsi dan Daerah Kabupaten/Kota yang mencakup 2 (dua) jenis pelayanan dasar yang berisi petunjuk teknis, yaitu rumah layak huni dan lingkungan yang sehat dan aman yang didukung prasarana, sarana dan utilitas umum (PSU). Peraturan tersebut dikeluarkan agar masing-masing pihak yang terlibat dalam pembangunan perumahan, baik developer maupun pemerintah yang bekerja sama dengan developer dapat mengikuti standar yang ditentukan dan masyarakat memperoleh perumahan yang layak, karena pembangunan perumahan yang tidak mengikuti standar rumah layak huni dapat merugikan konsumen. Karena kualitas bangunan merupakan hal terpenting dalam pembangunan perumahan, kualitas bangunan yang buruk selain merugikan dapat membahayakan penghuni rumah. Penelitian ini bertujuan untuk mengkaji kelayakan perumahan tipe 36 yang dibangun oleh PT. 
Toraa Graha Utama di Perumahan Hiu Putih XIV Kota Palangka Raya, Kalimantan Tengah berdasarkan Permenpera Nomor 22/Permen/M/2008.

\section{METODELOGI PENELITIAN}

Penelitian ini merupakan penelitian studi kasus dengan cara menganalisa fisik rumah dari segi eksterior rumah, mengajukan pertanyaan kepada pemilik rumah, serta mengajukan pertanyaan kepada konsultan perencana/pengawas. Pertanyaan-pertanyaan yang diajukan kepada pemilik rumah meliputi identitas pemilik rumah, kualitas bangunan dari segi struktur dan bahan bangunan, serta kondisi lingkungan rumah yang ditempati. Data tersebut diperoleh dari wawancara, studi literatur, serta observasi langsung pada objek penelitian. Metode yang di gunakan pada penelitian ini adalah metode kualitatif. Metode kualitatif adalah penelitian tentang riset yang bersifat deskriptif dan cenderung menggunakan analisis. Landasan teori dimanfaatkan sebagai pemandu agar fokus penelitian sesuai dengan fakta yang ada di lapangan, memberikan gambaran umum tentang latar penelitian dan sebagai bahan pembahasan hasil dari penelitian.

Penelitian akan dilakukan dengan metode kualitatif yaitu dengan studi kasus pada perumahan tipe 36 di Kota Palangka Raya sebanyak 30 rumah. Studi kasus dengan cara melakukan survei secara langsung ke perumahan milik PT. Toraa Graha Utama di Kota Palangka Raya dan mengidentifikasi perumahan tersebut berdasarkan Permenpera No. 22/PERMEN/M/2008, dilampiran II pada peraturan tersebut berisi indikator petunjuk teknis standar pelayanan minimal bidang perumahan rakyat daerah Kabupaten/Kota. Cara analisis data yang dilakukan dalam penelitian ini menggunakan tenknik analisis kualitatif Miles dan Huberman. Miles dan Huberman (1992), dalam buku mereka yang berjudul analisis data kualitatif menjelaskan secara mendalam cara data seharusnya dianalisa dalam penelitian kualitatif. Dalam penelitian kualitatif yang dirumuskan oleh Miles dan Huberman, analisis data kaulitatif adalah mereduksi data, menyajikan data dan menarik kesimpulan. Ketiga tahap yang direkomendasikan oleh Miles dan Huberman tersebut memperlihatkan bahwa analisis data dalam penelitian kualitatif adalah proses kategori data atau dengan kata lain proses menemukan pola atau tema-tema dan mencari hubungan antara kategori yang telah ditemukan dari hasil pengupulan data. Tiga tahap tersebut merupakan proses yang dilakukan dalam menganalisis data dalam penelitian kualitatif.

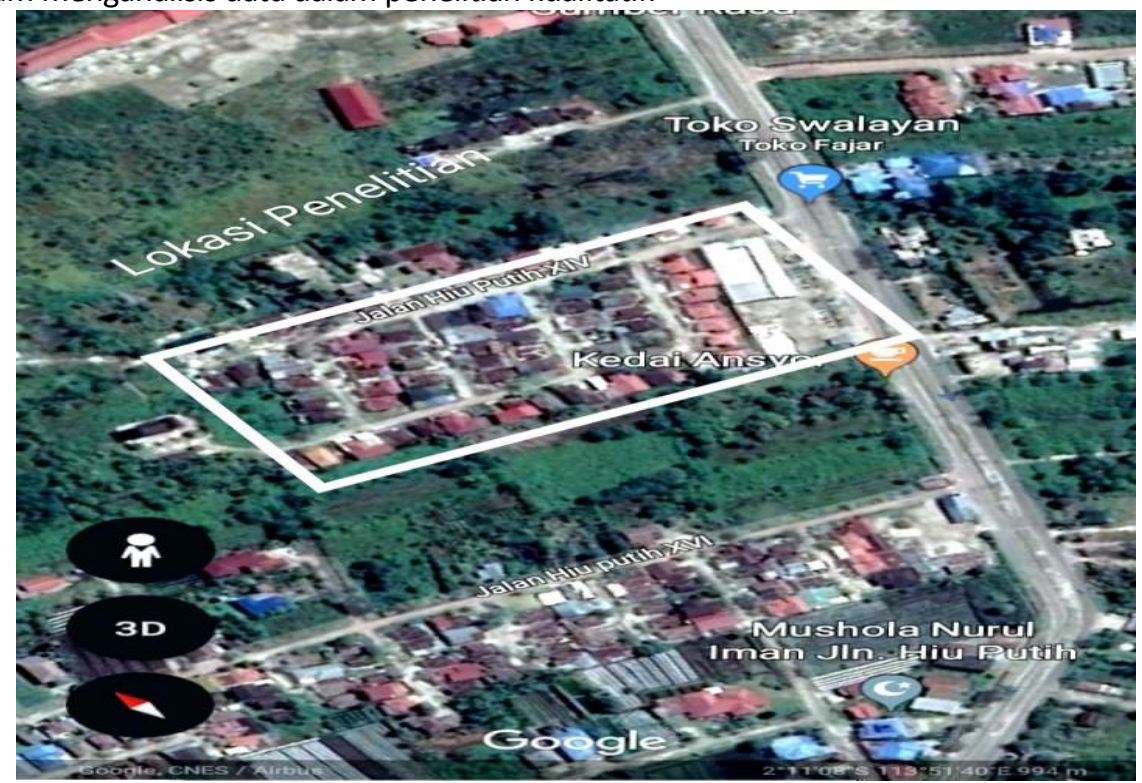

Gambar 1. Lokasi Penelitian (Sumber: Google Earth)

Pada saat melakukan penelitian di Jalan Hiu Putih XIV, peneliti berperan sebagai partisipan penuh, pengamat partisipan atau pengamat penuh. Penelitian ini dilakukan selama 7 hari. Sebelum melakukan penelitian, peneliti terlebih dahulu melakukan observasi lapangan guna mengetahui letak rumah yang akan diteliti dan pemlik rumah atau responden yang bersangkutan mengetahui jika akan ada penelitian di perumahan tersebut, agar kehadiran peneliti pada saat melakukan penelitian diketahui statusnya sebagai peneliti oleh responden atau informan penelitian. 
Sumber data yang digunakan dalam penelitian ini terdiri dari data primer dan data sekunder. Data primer diperoleh secara langsung dari lapangan atau sumber asli. Data primer dikumpulkan khusus dari studi kasus pengamatan lapangan secara informal yaitu survei fisik bangunan perumahan menggunakan tabel matriks pengamatan, wawancara/memberikan pertanyaan dengan pemilik rumah di perumahan yang akan diteliti, serta konsultan tentang perencanaan rumah tipe 36 tersebut. Data sekunder diperoleh dari literatur penunjang seperti internet, buku referensi, jurnal yang berhubungan dengan penelilitian.

Instrumen penelitian berupa kuesioner dan wawancara kepada narasumber. Kuesioner terdiri dari 4 (empat) bagian yaitu identitas responden, kriteria rumah layak huni, lingkungan yang sehat dan aman didukung prasarana sarana, tabel matriks pengamatan lapangan. Wawancara dilakukan secara langsung kepada pemilik rumah yang berada di perumahan tipe 36. Dalam hal ini, pemilik rumah mengisi daftar kolom-kolom untuk mengetahui kondisi rumah mereka. Pemeriksaan keabsahan data menggunakan teknik perpanjangan kehadiran peneliti di lapangan, observasi yang mendalam, trianggulasi (menggunakan sumber yang dapat dipercaya, metode, peneliti, teori), pembahasan sejawat, pelacakan kesesuian hasil, dan pengecekan anggota.

\section{HASIL DAN PEMBAHASAN}

Data penelitian diperoleh dari 30 responden dengan 2 jenis kusioner, yaitu kusioner tentang kriteria rumah layak huni dengan 7 butir pertanyaan dan lingkungan yang sehat dan aman yang didukung dengan prasarana, sarana dan utilitas umum dengan 14 butir pertanyaan. Responden meliputi 30 warga di perumahan Hiu Putih XIV milik PT. Toraa Graha Utama. Seluruh responden memberikan persepsinya sendiri sesuai dengan kenyataan di lapangan. Selain data sampel, diperoleh data arsip atau literatur berupa gambar perencanaan atau denah rumah serta matriks pengamatan lapangan. Data studi literatur/arsip tentang hal-hal yang berhubungan dengan studi kelayakan perumahan yang mengacu pada peraturan dan berbagai sumber tentang rumah layak huni.

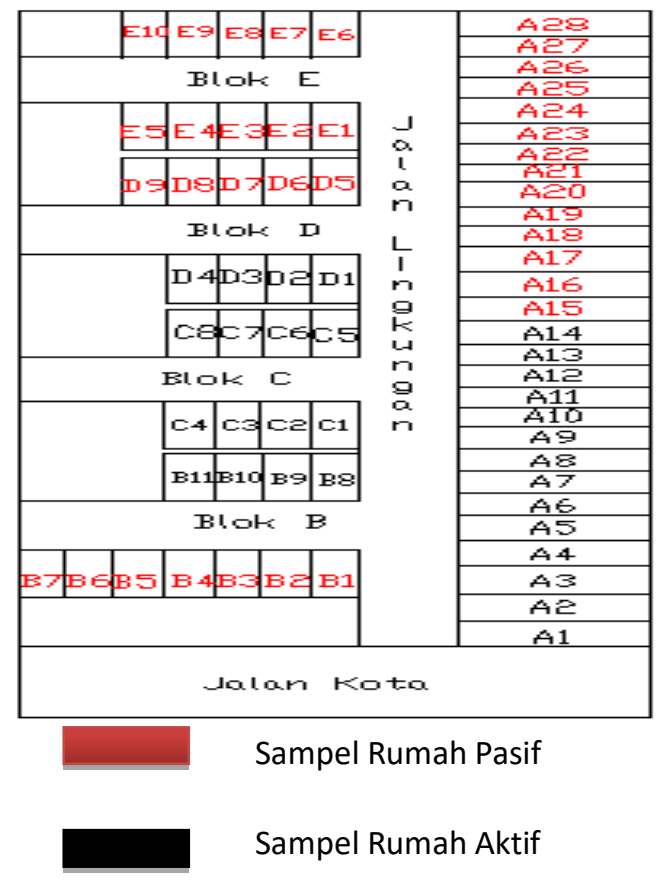

Gambar 2. Denah Perumahan Hiu Putih XIV

\section{Kriteria Rumah Layak Huni}

Kriteria rumah layak huni menurut Permenpera No. 22/PERMEN/M/2008 yang ditinjau adalah kriteria minimal rumah yang memenuhi persyaratan keselamatan bangunan, mulai dari ketentuan perencanaan struktur bawah sampai perencanaan struktur atas dapat diamati dari hasil data penelitian berupa gambar bestek rumah. Setelah itu dibandingkan dengan kondisi di lapangan dengan pengamatan secara langsung. 
Untuk struktur yang tertutup seperti pondasi, peneliti hanya mengecek dari gambar bestek apakah sesuai dengan peraturan yang ditinjau atau tidak.

Tabel 1. Lembar Jawaban Wawancara untuk Kriteria Rumah Layak Huni

\begin{tabular}{|c|c|c|c|c|c|c|c|c|}
\hline \multirow{4}{*}{ No } & \multicolumn{8}{|c|}{ Perumahan Hiu Putih XIV } \\
\hline & \multirow{3}{*}{$\begin{array}{c}\text { No } \\
\text { Sampel }\end{array}$} & \multicolumn{7}{|c|}{ Kriteria Rumah Layak Huni } \\
\hline & & \multicolumn{7}{|c|}{ Butir Pernyataan } \\
\hline & & B1 & B2 & B3 & B4 & B5 & B6 & B7 \\
\hline 1 & A1 & 4 & $\mathrm{~S}$ & $\mathrm{~S}$ & $\mathrm{~S}$ & $\mathrm{~S}$ & $\mathrm{~S}$ & $\mathrm{~S}$ \\
\hline 2 & $\mathrm{~A} 2$ & 6 & $\mathrm{~S}$ & $\mathrm{~S}$ & $\mathrm{~S}$ & $\mathrm{~S}$ & $\mathrm{~S}$ & SS \\
\hline 3 & A3 & 3 & $\mathrm{~S}$ & $\mathrm{~S}$ & $\mathrm{~S}$ & $\mathrm{~S}$ & $\mathrm{~S}$ & SS \\
\hline 4 & A4 & 5 & $\mathrm{~S}$ & $\mathrm{~S}$ & SS & $\mathrm{S}$ & $\mathrm{S}$ & SS \\
\hline 5 & A5 & 4 & $\mathrm{~S}$ & $\mathrm{~S}$ & $\mathrm{~S}$ & $\mathrm{~s}$ & $\mathrm{~S}$ & SS \\
\hline 6 & A6 & 4 & SS & $\mathrm{S}$ & $\mathrm{S}$ & $\mathrm{S}$ & $\mathrm{S}$ & SS \\
\hline 7 & A7 & 5 & $\mathrm{~S}$ & $\mathrm{~S}$ & $\mathrm{~S}$ & $\mathrm{~S}$ & $\mathrm{~S}$ & $\mathrm{~S}$ \\
\hline 8 & A8 & 4 & $S$ & $\mathrm{~s}$ & $\mathrm{~s}$ & $\mathrm{~s}$ & $\mathrm{~s}$ & SS \\
\hline 9 & A9 & 4 & $\mathrm{~s}$ & $\mathrm{~s}$ & $\mathrm{~s}$ & $\mathrm{~s}$ & $\mathrm{~s}$ & $\mathrm{~S}$ \\
\hline 10 & A10 & 5 & $\mathrm{~S}$ & $\mathrm{~S}$ & $\mathrm{~S}$ & $\mathrm{~S}$ & $\mathrm{~S}$ & SS \\
\hline 11 & A11 & 6 & $\mathrm{~S}$ & $\mathrm{~S}$ & $\mathrm{~S}$ & $\mathrm{~S}$ & $\mathrm{~S}$ & SS \\
\hline 12 & A12 & 5 & $\mathrm{~S}$ & $S$ & $\mathrm{~S}$ & $\mathrm{~S}$ & $\mathrm{~S}$ & $\mathrm{~S}$ \\
\hline 13 & A13 & 5 & $\mathrm{~S}$ & $S$ & $\mathrm{~S}$ & $\mathrm{~S}$ & $\mathrm{~S}$ & SS \\
\hline 14 & A14 & 5 & $\mathrm{~S}$ & $S$ & $\mathrm{~S}$ & $\mathrm{~S}$ & $\mathrm{~S}$ & SS \\
\hline 15 & B8 & 5 & $\mathrm{~S}$ & $S$ & $\mathrm{~S}$ & $\mathrm{~S}$ & $\mathrm{~S}$ & SS \\
\hline 16 & B9 & 2 & $\mathrm{~S}$ & $S$ & $\mathrm{~S}$ & $\mathrm{~S}$ & $\mathrm{~S}$ & $\mathrm{~S}$ \\
\hline 17 & B10 & 5 & $\mathrm{~S}$ & $S$ & $\mathrm{~S}$ & $\mathrm{~S}$ & $\mathrm{~S}$ & SS \\
\hline 18 & B11 & 5 & $\mathrm{~S}$ & $S$ & $\mathrm{~S}$ & $\mathrm{~S}$ & $S$ & $\mathrm{~S}$ \\
\hline 19 & $\mathrm{C} 1$ & 5 & $\mathrm{~S}$ & $S$ & $\mathrm{~S}$ & $\mathrm{~S}$ & $S$ & SS \\
\hline 20 & $\mathrm{C} 2$ & 4 & $\mathrm{~S}$ & $S$ & $\mathrm{~S}$ & $\mathrm{~S}$ & $S$ & SS \\
\hline 21 & C3 & 3 & $\mathrm{~S}$ & $S$ & $\mathrm{~S}$ & $\mathrm{~S}$ & $S$ & SS \\
\hline 22 & C4 & 3 & $\mathrm{~S}$ & $S$ & $\mathrm{~S}$ & $\mathrm{~S}$ & $\mathrm{~S}$ & $\mathrm{~S}$ \\
\hline 23 & C5 & 4 & $\mathrm{~S}$ & $S$ & $\mathrm{~S}$ & $\mathrm{~S}$ & $\mathrm{~S}$ & $S$ \\
\hline 24 & C6 & 4 & $\mathrm{~S}$ & $S$ & $\mathrm{~S}$ & $\mathrm{~S}$ & $\mathrm{~S}$ & $S$ \\
\hline 25 & $\mathrm{C} 7$ & 5 & $\mathrm{~S}$ & $S$ & $\mathrm{~S}$ & $\mathrm{~S}$ & $\mathrm{~S}$ & $\mathrm{~S}$ \\
\hline 26 & C8 & 5 & $\mathrm{~S}$ & $S$ & SS & $\mathrm{S}$ & $\mathrm{S}$ & SS \\
\hline 27 & D1 & 4 & $\mathrm{~S}$ & $S$ & $\mathrm{~S}$ & $\mathrm{~S}$ & $\mathrm{~S}$ & SS \\
\hline 28 & D2 & 4 & $\mathrm{~S}$ & $S$ & SS & $\mathrm{S}$ & $\mathrm{S}$ & SS \\
\hline 29 & D3 & 3 & S & $S$ & SS & $S$ & $\mathrm{~S}$ & SS \\
\hline 30 & D4 & 5 & $\mathrm{~S}$ & $S$ & $\mathrm{~S}$ & $\mathrm{~S}$ & $\mathrm{~S}$ & SS \\
\hline
\end{tabular}

(Sumber: Hasil Survei)

Butir pernyataan B1 (memenuhi kecukupan luas minimum), jumlah penghuni rumah $\leq 5$ orang sebanyak 28 rumah, dan $>5$ orang sebanyak 2 rumah. Butir pernyataan B2-B7 (menjamin kesehatan), jumlah setuju = 155 , sangat setuju $=25$, tidak setuju $=0$, sangat tidak setuju $=0$, total jawaban $=180$. Dari tabel 1 , hasil data sampel rumah pada butir pertanyaan B1 yaitu, untuk jumlah penghuni yang diatur pada Permenpera No. 22/PERMEN/M/2008 yang ditinjau tentang kecukupan luas minimum rumah layak huni antara 7,2 m2-12 m2/ orang. Sehingga didapat tipe 36 yang ditinjau disarankan penghuni rumah minimal 3 orang dan maksimal 5 orang dalam satu rumah. Dari 30 sampel yang diteliti, diperoleh 93,3\% (28 rumah) yang penghuninya sesuai standar minimal rumah layak huni maksimal 5 orang, dan 6,7\% (2 rumah) dengan nomor sampel 9A dan 46A yang pemilik rumah kurang dari standar minimal. Berikut rumus untuk mencari persen kelayakan per subindikator 


$$
=\frac{\text { Jumlah setuju \& sangat setuju }}{\text { Jumlah data }} \times 100 \%
$$

Informasi tentang menjamin kesehatan pada butir pertanyaan B2-B7, jumlah seluruh jawaban responden 180 jawaban yang mana 86,1\% atau 155 jawaban responden setuju, dan 13,9\% atau 25 jawaban responden sangat setuju bahwa perumahan yang mereka huni telah memenuhi kriteria layak huni. Sehingga dapat disimpulkan dari uraian tersebut $100 \%$ jawaban responden menggambarkan bahwa perumahan yang mereka tempati masuk kriteria minimal rumah layak huni.

Kriteria Lingkungan yang Sehat dan Aman Didukung Prasarana Sarana dan Utilitas Umum (PSU)

Hasil pengelompokkan data sampel pada Perumahan Hiu Putih seperti pada tabel 2

Tabel 2. Data Sampel Jawaban Lembar Wawancara Tentang PSU

\begin{tabular}{|c|c|c|c|c|c|c|c|c|c|c|c|c|c|c|c|}
\hline \multirow{4}{*}{ No } & \multirow{4}{*}{$\begin{array}{c}\text { No } \\
\text { Sampel }\end{array}$} & \multicolumn{14}{|c|}{ Perumahan Hiu Putih XIV } \\
\hline & & \multicolumn{14}{|c|}{ Lingkungan Sehat Dan Aman Yang Didukung Dengan PSU } \\
\hline & & \multicolumn{14}{|c|}{ Butir Pernyataan } \\
\hline & & C1 & $\mathrm{C2}$ & $C$ & c & CS & C & $\mathrm{c}$ & C8 & C9 & C10 & C11 & C12 & C13 & C14 \\
\hline 1 & A1 & $\mathrm{S}$ & $\mathrm{s}$ & $\mathrm{s}$ & $\mathrm{s}$ & ST & $\mathrm{TS}$ & & SS & $\mathrm{S}$ & $\mathrm{s}$ & $\mathrm{s}$ & TS & $\mathrm{s}$ & STS \\
\hline 2 & A2 & $\mathrm{S}$ & S & $\mathrm{S}$ & s & ST & $\mathrm{T}$ & s & SS & $\mathrm{S}$ & S & $\mathrm{S}$ & TS & $\mathrm{S}$ & TS \\
\hline 3 & A3 & S & $\mathrm{S}$ & $\mathrm{S}$ & $s$ & ST & $\mathrm{T}$ & & SS & $\mathrm{S}$ & $\mathrm{S}$ & $\mathrm{S}$ & TS & $\mathrm{S}$ & STS \\
\hline 4 & A4 & SS & $\mathrm{S}$ & $\mathrm{S}$ & $s$ & ST & $\mathrm{T}$ & & SS & $\mathrm{S}$ & $\mathrm{S}$ & $\mathrm{S}$ & TS & $\mathrm{S}$ & TS \\
\hline 5 & A5 & $\mathrm{S}$ & $S$ & $\mathrm{~S}$ & $s$ & ST & $\mathrm{T}$ & & SS & $\mathrm{S}$ & $\mathrm{S}$ & $S$ & TS & $S$ & STS \\
\hline 6 & A6 & $\mathrm{S}$ & $S$ & SS & s & ST & ST & & $\mathrm{S}$ & $\mathrm{S}$ & $S$ & SS & STS & $S$ & STS \\
\hline 7 & A7 & $\mathrm{S}$ & $S$ & S & $s$ & TS & $\mathrm{T}$ & & SS & $\mathrm{S}$ & $S$ & $S$ & TS & $S$ & STS \\
\hline 8 & A8 & $\mathrm{S}$ & $S$ & $S$ & $S$ & ST & $\mathrm{T}$ & & SS & $\mathrm{S}$ & $\mathrm{S}$ & $\mathrm{S}$ & TS & $\mathrm{S}$ & TS \\
\hline 9 & A9 & $\mathrm{S}$ & $S$ & $\mathrm{~S}$ & s & TS & $\mathrm{T}$ & & $S$ & $\mathrm{~S}$ & $\mathrm{~S}$ & $S$ & TS & $\mathrm{S}$ & TS \\
\hline 10 & A10 & $\mathrm{S}$ & $S$ & $\mathrm{~s}$ & $S$ & ST & $\mathrm{T}$ & s. & SS & $S$ & $\mathrm{~S}$ & $\mathrm{~S}$ & TS & $S$ & STS \\
\hline 11 & A11 & $\mathrm{S}$ & $S$ & $\mathrm{~S}$ & s & ST & $\mathrm{T}$ & & SS & $S$ & $S$ & $\mathrm{~S}$ & TS & $S$ & TS \\
\hline 12 & A12 & $S$ & $S$ & $S$ & $S$ & ST & $\mathrm{T}$ & & SS & $\mathrm{S}$ & $S$ & $S$ & TS & $S$ & STS \\
\hline 13 & A13 & $\mathrm{S}$ & $S$ & $\mathrm{~S}$ & $s$ & TS & $\mathrm{TS}$ & & $\mathrm{S}$ & $\mathrm{S}$ & $\mathrm{S}$ & $\mathrm{S}$ & TS & $\mathrm{S}$ & STS \\
\hline 14 & A14 & $\mathrm{S}$ & $S$ & $\mathrm{~S}$ & $S$ & ST & $T$ & & SS & $\mathrm{S}$ & $S$ & $S$ & TS & $S$ & STS \\
\hline 15 & B8 & $\mathrm{S}$ & $S$ & $S$ & $s$ & ST & $\mathrm{T}$ & & SS & $\mathrm{S}$ & $S$ & $\mathrm{~S}$ & TS & $S$ & STS \\
\hline 16 & B9 & $\mathrm{S}$ & $S$ & $\mathrm{~s}$ & $s$ & TS & $\bar{T}$ & & SS & $\mathrm{S}$ & $\mathrm{S}$ & $S$ & TS & $\mathrm{S}$ & TS \\
\hline 17 & B10 & $\mathrm{S}$ & $S$ & S & s & ST & ${ }^{T}$ & & SS & $\mathrm{S}$ & $\mathrm{S}$ & $S$ & TS & $S$ & TS \\
\hline 18 & B11 & $\mathrm{S}$ & $\mathrm{S}$ & $\mathrm{s}$ & s & TS & $\mathrm{T}$ & & SS & $\mathrm{S}$ & $\mathrm{S}$ & $\mathrm{S}$ & TS & $\mathrm{S}$ & TS \\
\hline 19 & $\mathrm{C} 1$ & $\mathrm{~S}$ & S & $\mathrm{S}$ & s & TS & $\mathrm{T}$ & & $\mathrm{S}$ & $\mathrm{S}$ & $\mathrm{S}$ & $\mathrm{S}$ & TS & $\mathrm{S}$ & TS \\
\hline 20 & $\mathrm{C} 2$ & $\mathrm{~S}$ & $S$ & $\mathrm{~s}$ & $s$ & ST & $\mathrm{T}$ & & SS & $\mathrm{S}$ & $\mathrm{S}$ & $\mathrm{S}$ & TS & $\mathrm{S}$ & STS \\
\hline 21 & C3 & $\mathrm{S}$ & $\mathrm{S}$ & $\mathrm{S}$ & $s$ & ST & $\mathrm{T}$ & & $S$ & $\mathrm{~S}$ & $\mathrm{~S}$ & $\mathrm{~S}$ & TS & $\mathrm{S}$ & TS \\
\hline 22 & C4 & $S$ & $S$ & $\mathrm{~S}$ & $S$ & TS & $\mathrm{T}$ & & SS & $S$ & $S$ & $S$ & TS & $S$ & TS \\
\hline 23 & C5 & $\mathrm{S}$ & $S$ & $\mathrm{~S}$ & $S$ & ST & $\mathrm{T}$ & & $S$ & $S$ & $S$ & $S$ & TS & $S$ & TS \\
\hline 24 & C6 & $\mathrm{S}$ & S & $S$ & $S$ & TS & $\mathrm{T}$ & & $S$ & $\mathrm{~S}$ & $S$ & $S$ & TS & $S$ & TS \\
\hline 25 & C7 & $\mathrm{S}$ & $S$ & $\mathrm{~S}$ & $s$ & TS & $\mathrm{T}$ & & SS & $\mathrm{S}$ & $\mathrm{S}$ & $\mathrm{S}$ & TS & $\mathrm{S}$ & TS \\
\hline 26 & $\mathrm{C} 8$ & SS & $\mathrm{S}$ & $\mathrm{s}$ & $S$ & ST & $\mathrm{T}$ & & SS & $\mathrm{S}$ & $S$ & $S$ & TS & $S$ & TS \\
\hline 27 & $\mathrm{D} 1$ & $\mathrm{~S}$ & $\mathrm{~S}$ & $\mathrm{~S}$ & $S$ & ST & $\mathrm{T}$ & & SS & $\mathrm{S}$ & $\mathrm{S}$ & $S$ & TS & $\mathrm{S}$ & TS \\
\hline 28 & $\mathrm{D} 2$ & $\mathrm{~S}$ & S & $\mathrm{s}$ & $s$ & ST & $\mathrm{T}$ & & SS & $\mathrm{S}$ & $\mathrm{S}$ & $\mathrm{S}$ & TS & $\mathrm{S}$ & TS \\
\hline 29 & D3 & $\mathrm{S}$ & $S$ & $\mathrm{~S}$ & $s$ & ST & T & & SS & $\mathrm{S}$ & $\mathrm{S}$ & $\mathrm{S}$ & TS & $\mathrm{S}$ & STS \\
\hline
\end{tabular}


ISSN 2443-227X

\begin{tabular}{|c|c|c|c|c|c|c|c|c|c|c|c|c|c|c|c|}
\hline \multirow{4}{*}{ No } & \multirow{4}{*}{$\begin{array}{c}\text { No } \\
\text { Sampel }\end{array}$} & \multicolumn{14}{|c|}{ Perumahan Hiu Putih XIV } \\
\hline & & \multicolumn{14}{|c|}{ Lingkungan Sehat Dan Aman Yang Didukung Dengan PSU } \\
\hline & & \multicolumn{14}{|c|}{ Butir Pernyataan } \\
\hline & & C1 & $\mathbf{C 2}$ & C3 & C4 & C5 & C6 & C7 & C8 & C9 & C10 & C11 & C12 & C13 & C14 \\
\hline 30 & D4 & $\mathrm{S}$ & $\mathrm{S}$ & $\mathrm{S}$ & $\mathrm{S}$ & STS & TS & $S$ & SS & $\mathrm{S}$ & $\mathrm{S}$ & $\mathrm{S}$ & TS & $\mathrm{S}$ & $\mathrm{TS}$ \\
\hline
\end{tabular}

(Sumber: Hasil Survei)

Butir pernyataan C1, C3, dan C4 (tentang ketentuan drainase) jumlah setuju $=87$, sangat setuju $=3$, tidak setuju $=0$, sangat tidak setuju $=0$, total jawaban $=90$. Butir pernyataan $\mathrm{C} 2$ (tentang ketentuan air bersih) jumlah setuju $=30$, sangat setuju $=0$, tidak setuju $=0$, sangat tidak setuju $=0$, total jawaban $=30$. Butir pernyataan C5 (tentang ketentuan persampahan) jumlah setuju $=0$, sangat setuju $=0$, tidak setuju $=8$, sangat tidak setuju 22, total jawaban $=30$. Butir pernyataan C6, C7, C8, C12, dan C14 (ketentuan tentang fasilitas umum) jumlah setuju $=37$, sangat setuju $=23$, tidak setuju $=76$, sangat tidak setuju = 14, total jawaban $=150$. Butir pernyataan C9, dan C10 (ketentuan tentang jalan) jumlah setuju $=60$, sangat setuju $=0$, tidak setuju $=0$, sangat tidak setuju $=0$, total jawaban $=60$. Butir pernyataan C11 (ketentuan tentang sanitasi) jumlah setuju $=$ 29 , sangat setuju $=1$, tidak setuju $=0$, sangat tidak setuju $=0$, total jawaban $=30$. Butir pernyataan $\mathrm{C} 13$ (ketentuan tentang listrik) jumlah setuju $=30$, sangat setuju $=0$, tidak setuju $=0$, sangat tidak setuju $=0$, total jawaban $=30$.

Untuk ketentuan drainase mewakili 3 butir pernyataan yaitu C1, C3, dan C4 pada lembar wawancara, dengan jumlah 90 , didapat $100 \%$ jawaban responden setuju dan sangat setuju bahwa saluran drainase itu berfungsi dengan baik. Ketentuan sumber air bersih mewakili 1 butir pernyataan yaitu C2 pada lembar wawancara, dengan jumlah 30 , diperoleh $100 \%$ jawaban responden setuju bahwa sumber air tersedia dan mencukupi kebutuhan sehari-hari. Ketentuan persampahan mewakili 1 butir pernyataan yaitu C5 pada lembar wawancara, dengan jumlah 30 , didapat $100 \%$ jawaban responden tidak setuju dan sangat tidak setuju bahwa tempat pembuangan sampah di lingkungan perumahan sudah disediakan, terkelola dan rutin dikosongkan oleh dinas kebersihan. Ketentuan fasilitas umum mewakili 5 butir pernyataan yaitu C6, C7, C8, C12, dan C14 pada lembar wawancara, dengan jumlah 150, didapat $100 \%$ jawaban responden tidak setuju dan sangat tidak setuju area hijau tersedia dan developer perumahan menyediakan ruang kosong pada halaman depan atau belakang untuk area hijau (C6 dan C14), 100\% jawaban responden setuju bahwa tempat ibadah dekat dengan lingkungan perumahan (C7), 100\% jawaban responden setuju dan sangat setuju tersedia pos keamanan/siskamling di dekat lingkungan perumahan, dan $100 \%$ jawaban responden tidk setuju dan sangat tidak setuju bahwa tersedia sumber air jika terjadi kebakaran di sekitar lingkungan perumahan. Kketentuan jalan mewakili 2 butir pernyataan yaitu C9 dan C10, diperoleh 100\% jawaban responden setuju bahwa jalan antar persil rumah sudah memadai dan berfungsi dengan baik serta akses jalan lingkungan bisa dilalui oleh mobil pemadam kebakaran. Ketentuan sanitasi mewakili 1 butir pernyataan yaitu C11, didapat 100\% jawaban responden setuju dan sangat setuju bahwa jarak septictank minimal $10 \mathrm{~m}$ dari sumur atau air rumah tangga. Ketentuan listrik mewakili 1 butir pernyataan yaitu C13, didapat 100\% jawaban responden setuju bahwa tersedia lampu penerangan jalan di sekitar lingkungan perumahan. Hasil ketercapaian sub-indikator dari Instrumen, dapat dilihat pada tabel 3

Tabel 3. Hasil Ketercapaian Sub-Indikator dari Instrumen

\begin{tabular}{|c|c|c|c|c|c|c|}
\hline \multirow[b]{2}{*}{ Variabel } & \multirow[b]{2}{*}{ Indikator } & \multirow[b]{2}{*}{$\begin{array}{l}\text { Sub- } \\
\text { Indikator }\end{array}$} & \multicolumn{2}{|c|}{ Jumlah Data } & \multicolumn{2}{|c|}{$\Sigma(\%)$} \\
\hline & & & S \& SS & $\begin{array}{l}\text { TS \& } \\
\text { STS }\end{array}$ & $\begin{array}{c}\text { Setuju dan } \\
\text { Sangat } \\
\text { Setuju }\end{array}$ & $\begin{array}{c}\text { Tidak Setuju } \\
\text { dan Sangat } \\
\text { Tidak Setuju }\end{array}$ \\
\hline \multirow{6}{*}{$\begin{array}{l}\text { Kajian } \\
\text { Tentang } \\
\text { Kelayakan } \\
\text { Perumahan } \\
\text { Komersial Tipe } \\
36 \text { Ditinjau }\end{array}$} & \multirow{4}{*}{$\begin{array}{l}\text { Kriteria Rumah Layak } \\
\text { Huni. } \\
\text { Rumus: }\end{array}$} & B1 & 28 & 2 & \multirow{6}{*}{$98 \%$} & \multirow{6}{*}{$2 \%$} \\
\hline & & B2 & 30 & & & \\
\hline & & B3 & 30 & & & \\
\hline & & B4 & 30 & & & \\
\hline & \multirow{2}{*}{$\frac{\text { Jumlah S \& SS }}{\text { Jumlah Data }}$ x 100\% } & B5 & 30 & & & \\
\hline & & B6 & 30 & & & \\
\hline
\end{tabular}




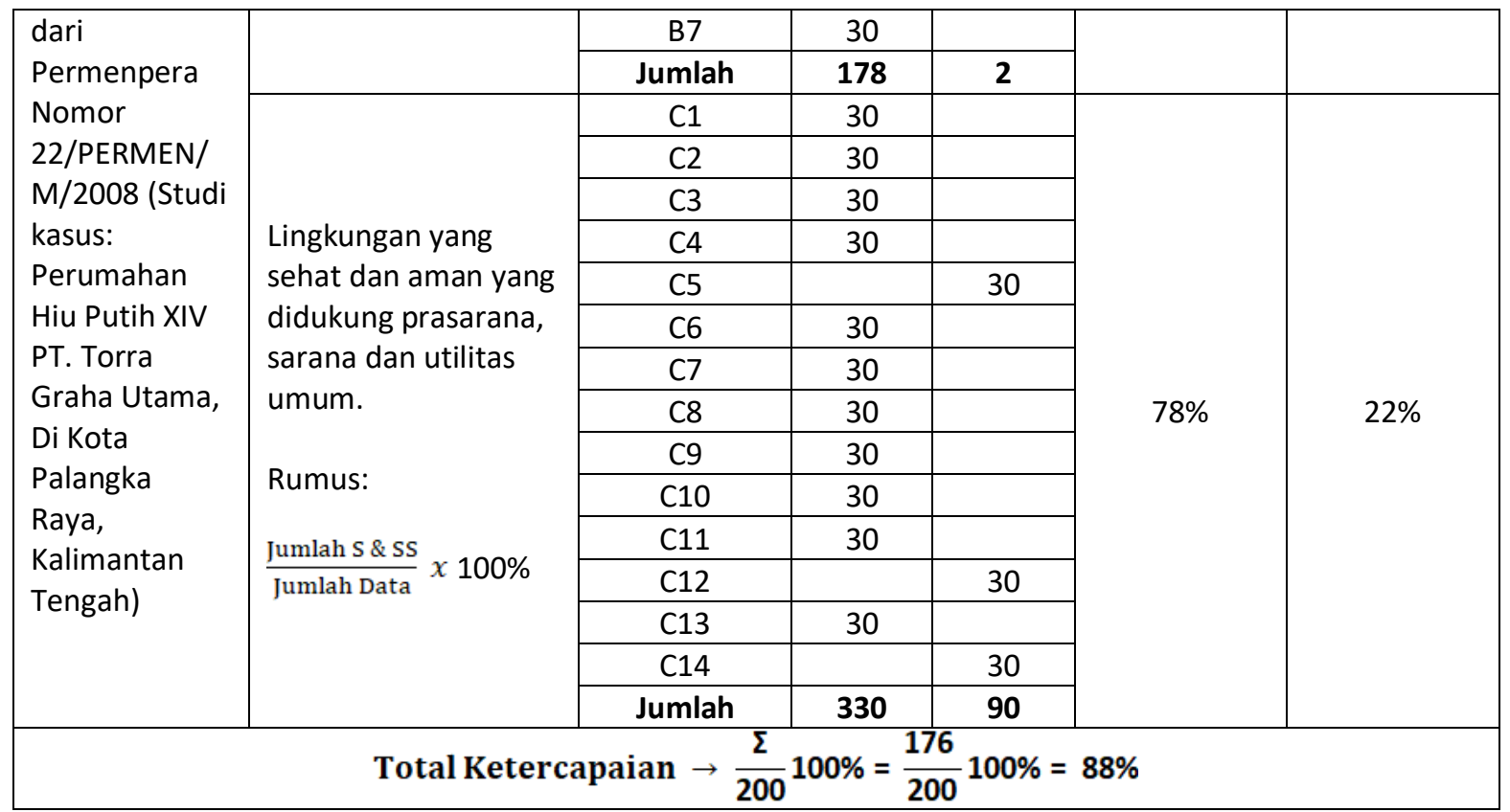

(Sumber: Hasil Perhitungan)

Berdasarkan tabel 3, dapat dijelaskan sebagai berikut:

1. Beberapa ketentuan yang berkaitan dengan rumah layak huni. Struktur bawah memenuhi persyaratan keselamatan bangunan dengan kondisi pondasi ditempatkan di dalam tanah keras dan tertanam di dalam tanah, struktur pondasi dihubungkan dengan sloof, serta pondasi diangkerkan. Struktur tengah memenuhi persyaratan keselamatan bangunan dengan kondisi bangunan menggunakan kolom, diangker, kolom diikat dan disatukan dengan balok/ringbalk supaya kaku, kuat dan kokoh. Struktur atas memenuhi persyaratan keselamatan bangunan dengan kondisi rangka kuda-kuda kuat menahan beban atap, kudakuda diangker dan atap diperkuat dengan tambahan ikatan angin diantara kuda-kuda. Ketentuan kesehatan memenuhi kriteria minimal untuk menjamin kesehatan dengan kondisi pencahayaan, penghawaan serta penyediaan sanitasi yang cukup. Memenuhi kecukupan luas minimum, sebagian besar jumlah penghuni atau 93,3\% rumah memenuhi atau sesuai dengan aturan yang telah disarankan peraturan.

2. Lingkungan yang sehat dan aman didukungn dengan PSU

Ketentuan jalan memenuhi kriteria akses jalan dapat diakses, dilalui, berfungsi dengan baik, konstruksi jalan tidak berbahaya bagi pejalan kaki, akses atas persil sekitar 0,8-2 $\mathrm{m}$, serta didukung dengan hasil wawancara responden dengan jawaban $100 \%$ setuju bahwa akses jalan antar persil rumah memadai, dapat dilalui mobil pemadam kebakaran. Limbah air hasil dari rumah tangga terhubung ke pembuangan drainase/parit, tidak menimbulkan bau dan jarak sumber air bersih dengan septictank $10 \mathrm{~m}$ atau lebih. Perumahan memiliki sistem drainase yang berfungsi dengan baik, serta didukung dengan hasil wawancara $100 \%$ responden setuju dan sangat setuju bahwa drainase perumahan tersebut berfungsi dengan baik. Tidak tersedianya tempat pembuangan sampah sementara di dekat perumahan tersebut serta didukung dengan wawancara $100 \%$ responden tidak setuju dan sangat tidak setuju bahwa tempat pembuangan sampah tersedia dan terkelola dengan baik. Sumber air bersih mencukupi dan mudah diperoleh, serta didukung dengan wawancara $100 \%$ setuju bahwa air bersih mudah didapat dan mencukupi untuk kebutuhan sehari-hari. Setiap rumah disuplai daya listrik sebebesar 900 VA, gardu listrik menjamin keamanan, serta tersedia penerangan jalan yang didukung dengan wawncara $100 \%$ responden setuju bahwa tersedia lampu penerangan jalan di sekitar lingkungan perumahan. Fasilitas umum seperti tempat ibadah terjangkau dengan jarak dari perumahan ke tempat ibadah (mushola) sekitar $\pm 200 \mathrm{~m}$ (gereja) sekitar $\pm 2 \mathrm{~km}$, terjangkau sarana pendidikan dengan jarak dari perumahan sekitar $\pm 500 \mathrm{~m}$ untuk Perguruan Tinggi terdekat dan sekitar $1 \mathrm{~km}$ untuk SMP terdekat. 
Tabel 4. Kondisi Perumahan Hiu Putih XIV

\begin{tabular}{|c|c|c|c|}
\hline \multirow{2}{*}{ No } & \multirow{2}{*}{ Ketentuan } & \multicolumn{2}{|c|}{ Perumahan Hiu Putih XIV } \\
\hline & & Memenuhi & Tidak Memenuhi \\
\hline \multicolumn{4}{|c|}{ I. Rumah Layak Huni } \\
\hline 1 & Struktur Bawah & $\sqrt{ }$ & \\
\hline 2 & Struktur Tengah & $\mathrm{V}$ & \\
\hline 3 & Struktur Atas & $\sqrt{ }$ & \\
\hline 4 & Kesehatan Minimal & $\sqrt{ }$ & \\
\hline 5 & Kecukupan Luas Minimum & $\mathrm{V}$ & \\
\hline \multicolumn{4}{|c|}{ II. Lingkungan yang Sehat dan Aman Didukung PSU } \\
\hline 1 & Akses Jalan & $\mathrm{V}$ & \\
\hline 2 & Sanitasi & $\sqrt{ }$ & \\
\hline 3 & Drainase & $\sqrt{ }$ & \\
\hline 4 & Persampahan & & $\mathrm{V}$ \\
\hline 5 & Air Bersih & $\sqrt{ }$ & \\
\hline 6 & Listrik & $\sqrt{ }$ & \\
\hline 7 & Fasilitas Umum & $\sqrt{ }$ & \\
\hline
\end{tabular}

\section{PENUTUP}

KESIMPULAN

1. Perumahan Hiu Putih XIV sudah menerapkan kriteria minimal rumah layak huni serta lingkungan yang sehat dan aman didukung dengan tersediannya prasarana, sarana dan utilitas umum di lingkungan tersebut. Total ketercapaian dari jawaban responden mengenai rumah layak huni dan lingkungan sehat dan aman serta didukung dengan PSU didapat $88 \%$ kelayakan.

2. Perumahan Hiu Putih XIV sudah menerapkan ketentuan minimal rumah layak huni serta memenuhi persyaratan keselamatan bangunan, kecukupan minimum luas bangunan serta kesehatan penghuninya sesuai dengan Permenpera Nomor 22/Permen/M/2008 dengan hasil ketercapaian sub-indikator dari instrumen hasil wawancara dengan responden mencapai $98 \%$ yang menjawab setuju dan sangat setuju sedangkan $2 \%$ yang menjawab tidak setuju dan sangat tidak setuju.

3. Perumahan Hiu Putih XIV sudah menerapkan kriteria minimal lingkungan yang dilengkapi dengan prasarana lingkungan dengan hasil ketercapaian sub-indikator dari instrumen hasil wawancara dengan responden mencapai $78 \%$ yang menjawab setuju dan sangat setuju, sedangkan $22 \%$ responden menjawab tidak setuju dan sangat tidak setuju tersediannya area hijau, tersedia sumber air jika terjadi kebakaran dan tempat pembuangan sampah yang terkelola. Untuk sarana lingkungan lainnya dan fasilitas umum terdekat cukup terjangkau seperti sarana pendidikan, tempat peribadatan, serta tersedia minimarket.

\section{DAFTAR PUSTAKA}

[1] Dyah Swastantika (2018). Kelebihan Dan Kekurangan Rumah Tipe 36, 45, Dan 60. Diunduh pada tanggal 29, April 2019; 01:20 dari https://www.homify.co.id.

[2] Dwi Putra Perdana (2013) "Studi Tentang Pelaksanaan Program Pelayanan dan Rehabilitasi Kesejahteraan Sosial Rumah Layak Huni di Desa Tideng Pale Induk, Kecamatan Sesayap Kabupaten Tana Tidung".

[3] Miles, Mathew B. Dan Huberman, A., Michel, (1992). Analisa Data Kualitatif (diterjemahkan oleh Tjejep Rohendi Rohidi), Jakarta : UI-Press.

[4] Peraturan Menteri Negara Perumahan Rakyat No: 22/PERMEN/M/2008 tentang Standar Pelayanan Minimal Bidang Perumahan Rakyat Daerah Provinsi Dan Daerah Kabupaten Kota. Diunduh tanggal 08/05/201915.25,darihttp://dispkp.sumutprov.go.id>2016/Permen:Kepmenpera/Pemenpera/2008/Perm en\%2022\%20Tahun\%202008.pdf 
[5] Prihartini Putri (2015) “Kajian Tentang Kelayakan Perumahan Komersial Tipe 36 Di Tinjau Dari Permenpera Nomor 22/PERMEN/M/2008 (Studi Kasus : Perumahan Pondok Pinang Hijau CV. Mandiri Bangun Sentosa dan Perumahan Pasir Panjang Permai PT. Mandiri Bangun Karya di Kabupaten Kotawaringin Barat, Kalimantan Tengah).

[6] Ruli Khusnu Rizki (2010) "Evaluasi Pelaksanaan Program Perbaikan Rumah Tidak Layak Huni Di Kota Surakarta".

[7] Tim Penyusun FKIP UPR. (2017). Pedoman Penulisan Skripsi. Palangka Raya: Universitas Palangka Raya.

[8] Miles, Mathew B. Dan Huberman, A., Michel, (1992), Analisa Data Kualitatif (diterjemahkan oleh Tjejep Rohendi Rohidi), Jakarta: UI-Press 